\title{
PULMONARY VASODILATOR EFFECTS OF NOREPINEPHRINE IN COMBINATION WITH HIGH EPIDURAL ANALGESIA DURING THE THORACOSCOPIC CORRECTION OF ESOPHAGEAL ATRESIA
}

A. Keyan MD, M. Shakaryan MD, PhD

"Sourb Astvatsamayr" Medical Centre, Yerevan, Armenia

\section{Goals}

Evaluation of the respiratory and the pulmonary circulatory effects of Norepinephrine (NE) infusion in combination with high epidural analgesia (EA) in newborns

- $\quad$ Change dynamics of SpO2 after surgery start, onelung ventilation in patient on side position.

- Demonstration of possibility to decrease FiO2 as a pulmonary circulatory effects manifestation.

\section{Methods}

- 10 newborns, gestation age $35 \pm 3$ weeks, birth weight $2800 \pm 700 \mathrm{~g}$ were scheduled for thoracoscopic correction of esophageal atresia.

- Surgeries were taken under the high EA as a component of general anesthesia with infusion of NE.

- Single shot EA (20G Touchy needle) on the level Th4-Th5 Sol.Bupivacaini 0,1\%-0,3ml/kg

- General Anesthesia (GA) was maintained by Sevorane, Atracurium.

- NE 0,3-1 mkg/kg/min.

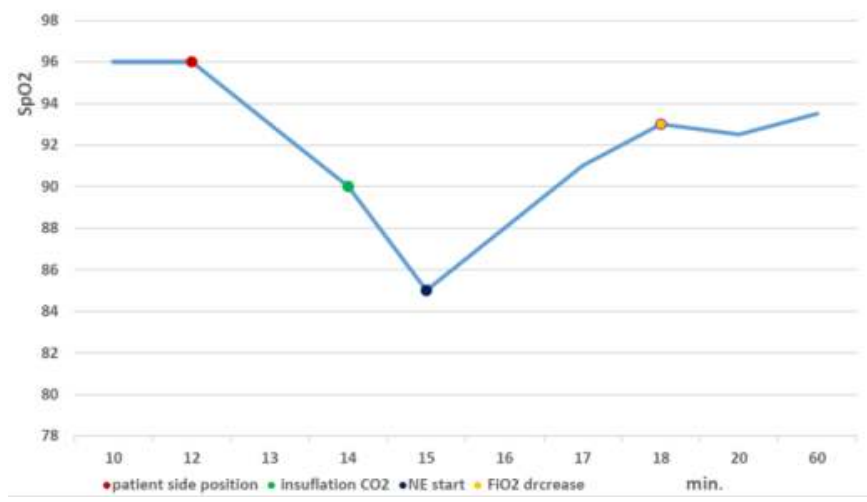

Fig.1

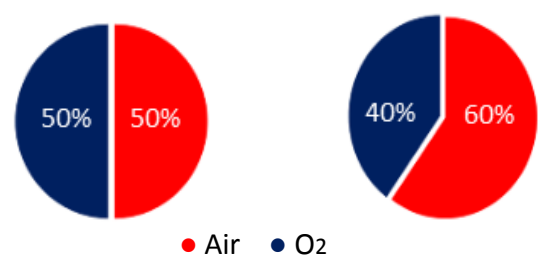

Fig.2 warming

\section{Results}

- GA, patient on side position, $\mathrm{CO} 2$ insufflation, one-lung ventilation initiate decrease $\mathrm{SpO} 2$ till $85 \pm 2 \%$. The single shot EA and start of prolonged infusion of NE could bring to SpO2 increase till $93 \pm 3 \%$. (Fig.1)

- The single shot EA and start of prolonged infusion of NE during the thoracoscopic correction of esophageal atresia makes possible to decrease $\mathrm{FiO} 2$ from $50 \%$ to $40 \%$ without decreasing SpO2. (Fig,2)

- After starting NE the BP and HR increased for 20,2 \pm 3.8 $\mathrm{mm} \mathrm{Hg}$ and 8,4 $\pm 1,6 \mathrm{r} / \mathrm{min}$ respectively.

\section{Conclusion}

NE in condition with effective high epidural analgesia may improve lung function in newborn with pulmonary hypertension (induced by thoracoscopy), increase $\mathrm{SpO} 2$ with following possibility to decrease $\mathrm{FiO} 2$ in $10 \%$.

\section{Discussion}

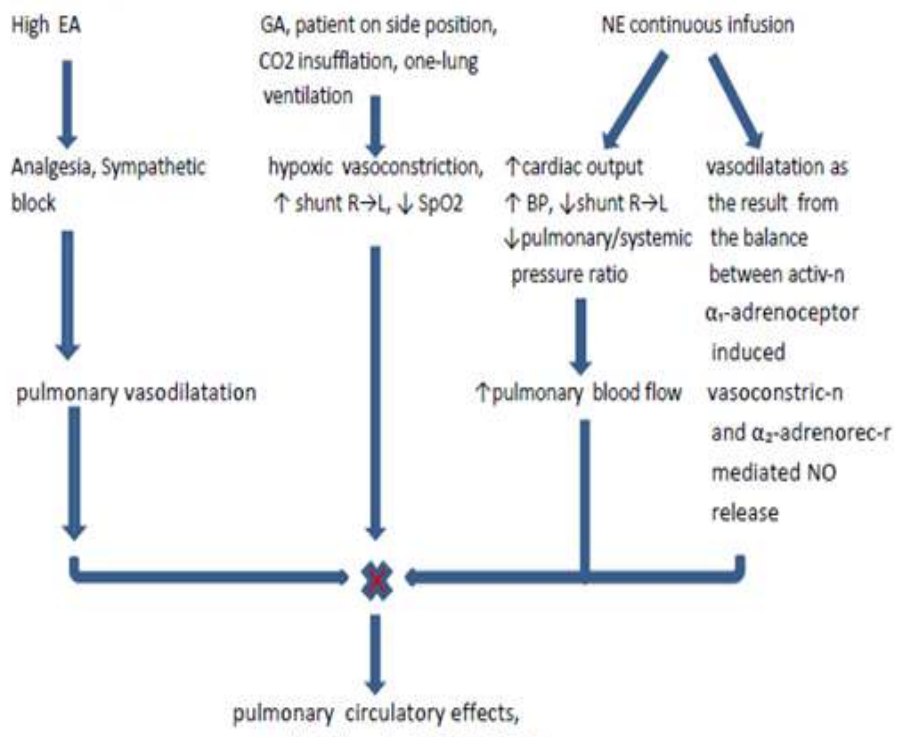

\section{References}

- Groeben H., (2006), Epidural anesthesia and pulmonary function, Journal of Anaesthesia 20(4): 290-299

- Reda S. Abdelrahman (2012), Effects of thoracic epidural anesthesia on pulmonary venous admixture and oxygenation with isoflurane or propofol anesthesia during one lung ventilation, Egyptian Journal of Chest Diseases and Tuberculosis 61(4): 477-483

- Pierre Tourneux et al. (2008), Pulmonary Circulatory Effects of Norepinephrine in Newborn Infants with Persistent Pulmonary Hypertension, The Journal of Pediatrics 153(3): 345-349 